\title{
Effect of drying methods on the texture properties and active ingredients in Longan flesh
}

\author{
LI Qian ${ }^{1 *}$, LV Yongbin ${ }^{1}$, SU Keying ${ }^{1}$, LUO Simei ${ }^{1}$, ZHAO Shiming ${ }^{1}$, LI Ruiting ${ }^{1}$, ZHONG Wanming ${ }^{1}$, HUANG Shangzhen ${ }^{1}$ \\ ${ }^{1}$ Department of Logistics, Guangzhou College of Technology and Business, Guangzhou,510850, China
}

\begin{abstract}
In order to determine the best drying method of longan flesh, the effects of different drying method (microwave drying, blast drying,vacuum freeze-drying ) on the texture characteristics and active ingredients were compared. The results show that different drying methods will increase the hardness, cohesion and chewiness of longan flesh, and decrease the viscosity and elasticity to varying degrees. For active substances, the content of flavonoids and polyphenols is the largest under vacuum freeze-drying, followed by microwave drying and blast drying, but the loss of vitamin $\mathrm{C}$ is the opposite. On the whole, vacuum freeze-drying does not cause shrinkage of the flesh, and maintains good hardness, cohesion, chewiness and active ingredients. Comprehensive texture characteristics and changes in active ingredients, vacuum freeze drying is more suitable for drying and processing longan flesh.
\end{abstract}

\section{Introduction}

Longan is a subtropical fruit with unique flavor. which has both edible and medicinal value ${ }^{[1]}$. Longan is rich in glucose that can be directly absorbed by humans, which can quickly replenish energy, restore energy and relieve fatigue In addition, a variety of minerals such as calcium, phosphorus, potassium, iron, etc. can promote the production of human hemoglobin, prevent and treat anemia, enhance human immunity and disease resistance, relieve symptoms such as palpitations, palpitation, insomnia, and forgetfulness, and stimulate the brain Cell activity, brain health and intelligence ${ }^{[2-3]}$, longan also has anti-oxidation, scavenging free radicals in the body, and delaying aging ${ }^{[4-}$ ${ }^{6}$. Since longan is easy to rot and cannot be stored, it is not conducive to transportation and sales. Therefore, in addition to being sold as a fruit, longan is often processed into dehydrated fruit, canned fruit, fruit wine, fruit pulp ${ }^{[7-}$ 8].

At present, the commonly used drying methods for Fruits and vegetables include: solarization, microwave drying[9], blast drying ${ }^{[10]}$, vacuum drying ${ }^{[1]}$, vacuum freeze drying ${ }^{[12]}$ and so on. Microwave drying is a method of internal heating. When the wet material is in the microwave high-frequency electric field with a very short oscillation period, the water molecules inside it will be polarized and arranged neatly along the direction of the microwave electric field, and then quickly rotate with the alternating changes in the direction of the high-frequency alternating electric field, and Violent collision and friction are produced, as a result, part of the microwave energy is converted into molecular kinetic energy and expressed in the form of heat, which makes the temperature of the water rise and leave the material, thereby drying the material. Blast drying is to make the air in the box convectively circulate. Without affecting the temperature of the working room, the fresh air outside the box is continuously sucked into the box from the uniquely designed air inlet duct, heating and circulating, and exhaust gas is generated from the exhaust Drain out of the box from the hole. Through the continuous exchange of indoor and outdoor air, so as to achieve the purpose of drying. Water has three phases: solid, liquid, and gas.According to the phase equilibrium theory in thermodynamics, as the pressure decreases, the freezing point of water does not change much, but the boiling point gets lower and lower, approaching the freezing point. When the pressure drops to a certain degree of vacuum, the boiling point and freezing point of water coincide, and the ice can be directly vaporized into gas without being liquid. This process is called sublimation.The vacuum freeze-drying of food means that the frozen water in the food is sublimated and removed under the condition of low temperature and low pressure below the triple point of water.These drying methods have their own advantages and disadvantages. The use of thermal processing is simple and the equipment cost is low. However, heating will destroy the active ingredients of longan, such as vitamins, and will also cause browning of the flesh ${ }^{[13]}$. Vacuum freezedrying is to turn the water in the sample into a solid state at a low temperature, and then sublimate it into a gaseous state under a vacuum ${ }^{[14]}$. Since it does not need to be dried at a high temperature, it can retain the color, fragrance, taste, and nutrients of the pulp to the greatest extent. This paper studies the three most common drying methods: microwave drying, blast drying, and vacuum freeze drying have an effect on the texture properties (hardness, viscosity, cohesion, elasticity, chewiness) and active ingredients (flavonoids, polyphenols, vitamins C) in 
longan flesh. The purpose is to provide an important theoretical basis for the drying of longan flesh.

\section{Materials and method}

\subsection{Plant material}

Longan: Fresh longan bought from the local market;

Longan peeled off the shell, cored, cut into two pieces of equal size, and used as longan flesh for later use.

\subsection{Chemical}

Rutin; Gallic acid; Ascorbic acid; Folinol; Sodium hydroxide; Aluminum nitrate; Sodium nitrite; Sodium carbonate; Glycerin; Ammonium Acetate; Lead Nitrate; Thioacetamide; Hydrochloric Acid Solution; Ammonia Solution; were utilized.

\subsection{Drying method}

Divide the longan flesh into 4 groups, each 100 g, group A is fresh flesh, group B is microwave drying (140w, 60min), group $\mathrm{C}$ is blast drying $\left(65^{\circ} \mathrm{C}, 24 \mathrm{~h}\right)$, group $\mathrm{D}$ is vacuum freezing drying $\left(-65^{\circ} \mathrm{C}, 0.4 \mathrm{Kpa}, 72 \mathrm{~h}\right)$

\subsection{Determination of weight loss rate}

Weigh the dried sample and calculate the weight loss rate, repeat three times to take the average.

Weight loss rate $=(\mathrm{W} 1-\mathrm{W} 2) / \mathrm{W} 1 * 100 \%$.

$\mathrm{W} 1$ is the weight of the sample before drying,

W2 is the weight of the sample after drying.

$\mathrm{W} 1-\mathrm{W} 2$ is the weight lost during drying

\subsection{Determination of the texture properties}

The longan flesh was measured with a texture analyzer. A flat-bottomed cylindrical probe TA9 with a diameter of $10 \mathrm{~mm}$ was used. The measurement conditions were: test speed $5 \mathrm{~mm} / \mathrm{s}$, compression distance $10 \mathrm{~mm}$, dwell time between two compressions $5 \mathrm{~s}$, compression force $5 \mathrm{~g}$, The test was repeated 10 times to obtain the texture characteristic parameters: hardness, viscosity, cohesion, elasticity, chewiness.

\subsection{Determination of active ingredients}

Flavonoids, Polyphenol determination with reference to the methods of Vongsak ${ }^{[15]}$ and Salari ${ }^{[16]}$, The Vitamin C is determined by reference to GB 14754-2010.

\subsection{Experimental data processing}

The data were processed and analyzed by Origin 9.0and SPSS 22.0 software. All the experiments were repeated three times. The experimental results were expressed as mean \pm standard deviation.

\section{Results and discussion}

\subsection{Effects of different drying methods on the weight loss rate of longan flesh}

The weight loss rate of longan flesh in different drying methods is shown in Fig 1. After the longan is dried, the moisture is lost to varying degrees, and the mass weight loss rate is above $75 \%$. Among them, the blast drying weight loss rate is the highest at $79.8 \%$, followed by vacuum freeze drying and microwave drying.

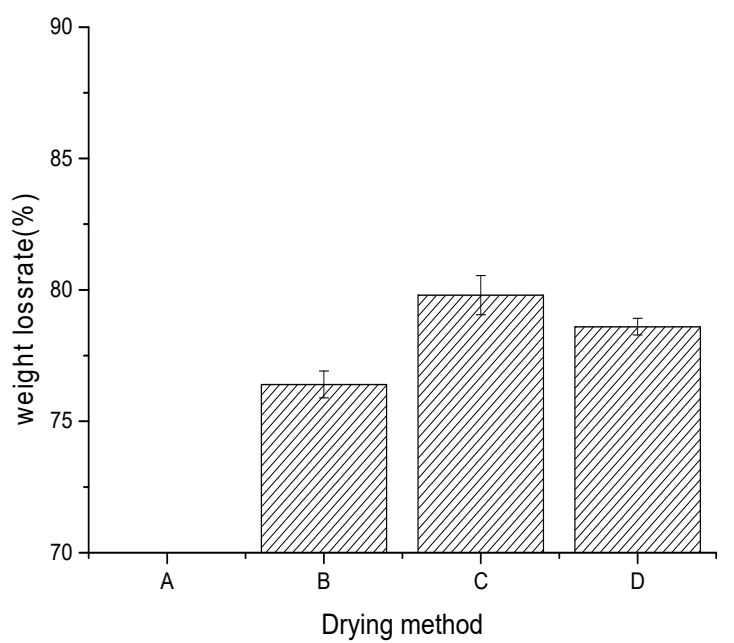

Fig.1 Effects of different drying methods on the weight loss rate of longan flesh

\subsection{Effects of different drying methods on the texture characteristics of longan flesh}

The texture parameters of longan directly reflect the taste when people eat it. Tab1 shows that the texture parameters change differently under different drying methods. After drying, the stickiness of longan is gone. It may be that the longan has no time to spread to the surface due to the rapid drying. After microwave drying, the hardness of longan is the largest, and the cohesion, elasticity, and chewiness are the smallest. Such a product is not chewy and has a poor taste. After blast drying, the hardness is minimum, elasticity, chewiness is moderate, and the mouthfeel is relatively soft. After vacuum freeze-drying, the sample formed a porous structure with high chewiness, moderate hardness and good taste.

Table.1 Effects of different drying methods on the texture characteristics of longan flesh

\begin{tabular}{|c|c|c|c|c|}
\hline \multirow[t]{2}{*}{ Index } & \multicolumn{4}{|c|}{ Drying method } \\
\hline & Fresh & $\begin{array}{l}\text { Microwa } \\
\text { ve }\end{array}$ & $\begin{array}{l}\text { fan- } \\
\text { drying }\end{array}$ & $\begin{array}{l}\text { Vacuum } \\
\text { freeze }\end{array}$ \\
\hline $\begin{array}{l}\text { hardness } \\
(\mathrm{g})\end{array}$ & $\begin{array}{l}1578.67 \pm \\
319.51\end{array}$ & $\begin{array}{l}4656.57 \pm \\
973.43\end{array}$ & $\begin{array}{l}3654 \pm 2 \\
73.96\end{array}$ & $\begin{array}{l}4107.50 \pm \\
717.04\end{array}$ \\
\hline $\begin{array}{l}\text { Stickines } \\
\mathrm{s}(\mathrm{mJ})\end{array}$ & $0.21 \pm 0.09$ & - & - & - \\
\hline Cohesion & $0.16 \pm 0.03$ & $0.31 \pm 0.03$ & $\begin{array}{l}0.32 \pm 0 . \\
06\end{array}$ & $0.37 \pm 0.08$ \\
\hline $\begin{array}{l}\text { Elasticity } \\
(\mathrm{mm})\end{array}$ & $6.09 \pm 0.73$ & $2.32 \pm 0.12$ & $\begin{array}{l}2.54 \pm 0 . \\
22\end{array}$ & $3.01 \pm 0.34$ \\
\hline
\end{tabular}




\begin{tabular}{lllll}
\hline Chewine & $15.63 \pm 2.7$ & $35.12 \pm 8.1$ & $37.6 \pm 5$. & $45.71 \pm 3.7$ \\
ss(mJ) & 3 & 5 & 76 & 6 \\
\hline
\end{tabular}

\subsection{Effects of different drying methods on active ingredients of longan flesh}

\subsubsection{Effects of different drying methods on the content of flavonoids of longan flesh}

The flavonoids in fruits are unstable and are easily affected by temperature and oxidation $\left.{ }^{[17}\right]$.Fig2 shows the changes in total flavonoids content of longan after different drying methods. After vacuum freeze-drying, the flavonoid content in the sample is the highest, $6.73 \mathrm{mg} / 100 \mathrm{~g}$, which may be due to the effective reduction of flavonoid oxidation and decomposition under low temperature and vacuum conditions. After blast drying, the loss of flavonoids was the largest, $4.59 \mathrm{mg} / 100 \mathrm{~g}$. This may be due to longan exposure to the air for a long time, and high temperature accelerated the oxidative decomposition of flavonoids.weight loss rate of longan flesh in different drying methods is shown in Fig 1.After the longan is dried, the moisture is lost to varying degrees, and the mass weight loss rate is above $75 \%$. Among them, the blast drying weight loss rate is the highest at $79.8 \%$, followed by vacuum freeze drying and microwave drying.

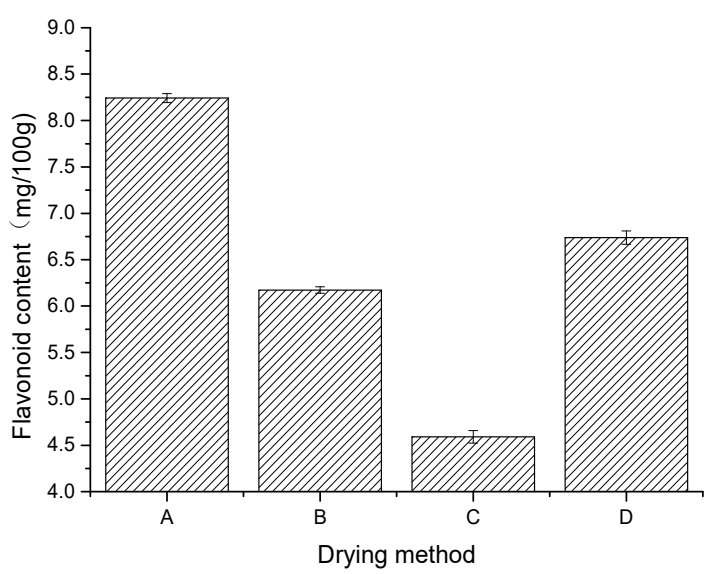

Fig.2 Effects of different drying methods on the content of flavonoids of longan flesh

\subsubsection{Effects of different drying methods on the content of polyphenols of longan flesh}

Fig 3 shows the changes in the content of polyphenols under different drying methods. The degree of loss is: blast $>$ microwave $>$ vacuum freeze-drying, and the content is $15.23 \mathrm{mg} / 100 \mathrm{~g}, 17.87 \mathrm{mg} / 100 \mathrm{~g}, 23.69 \mathrm{mg} / 100 \mathrm{~g}$, which can be seen, Vacuum drying can retain the active ingredients to the greatest extent. This is because under the action of high temperature and oxygen, the enzymatic browning of polyphenol oxidase is promoted ${ }^{[18]}$.

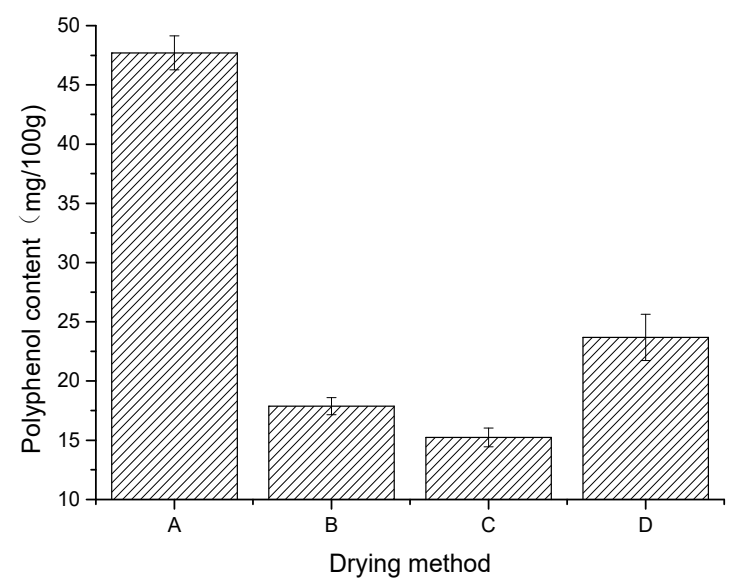

Fig.3 Effects of different drying methods on the content of polyphenols of longan flesh

\subsubsection{Effects of different drying methods on the content of Vc of longan flesh}

Vitamin $\mathrm{C}$ is a typical active substance of fruits and vegetables. It has anti-oxidation and anti-inflammatory effects. Figure 4 shows that after drying, the content of Vitamin $C$ is greatly reduced. Among them, the loss was the largest after microwave drying, the content $2.15 \mathrm{ug} / \mathrm{g}$, and the loss rate $92.45 \%$,followed by vacuum freeze drying and blast drying. This may be because vitamin $\mathrm{C}$ is a water-soluble substance, which tends to decrease with the loss of water, and its structure is unstable and easily affected by high temperature and oxygen ${ }^{[19]}$.

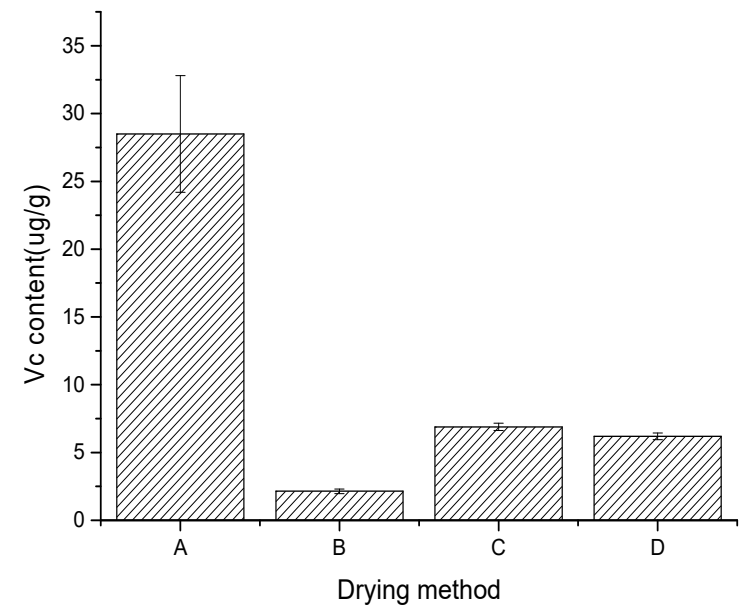

Fig.4 Effects of different drying methods on the content of Vc of longan flesh

\section{Conclusion}

After longan flesh is dried in different ways, there are great differences in its texture characteristics and active substance content. In terms of texture, after drying, the stickiness disappears. The sample after being vacuumfrozen has no browning, moderate hardness, good chewiness, and good taste. After blast drying, the sample 
has low hardness and soft taste. After microwave drying, the sample has high hardness, low chewiness and poor taste. In terms of active substances, the contents of flavonoids, polyphenols, and vitamin $\mathrm{C}$ in the samples after vacuum freeze-drying are generally higher than the other two, indicating that high temperature and oxygen are not conducive to the retention of active substances.

\section{References}

1. Pham V T, Herrero M , Hormaza J I . Effect of temperature on pollen germination and pollen tube growth in longan (Dimocarpus longan Lour.)[J]. Scientia Horticulturae, 2015, 197:470-475.

2. Castillo-Castillo Y, Ruiz-Barrera O, Burrola-Barraza $\mathrm{M} \mathrm{E}$, et al. The isolation and characterization of polysaccharides from longan pulp[J]. Brazilian Journal of Microbiology, 2016, 47(4):889-895.

3. Liu, Chang, Lai, et al. Structure, antioxidant and alpha-amylase inhibitory activities of longan pericarp proanthocyanidins $[\mathrm{J}]$. Journal of Functional Foods, 2015. 14:23-32

4. $\mathrm{Mu}, \mathrm{Yu}, \mathrm{Cai}$, et al. Chemical characterization and antihyperglycaemic effects of polyphenol enriched longan (Dimocarpus longan Lour.) pericarp extracts[J]. Journal of Functional Foods, 2015.

5. Rong $\mathrm{Y}$, Yang $\mathrm{R}$, Yang $\mathrm{Y}$, et al. Structural Characterization of an Active Polysaccharide of Longan and Evaluation of Immunological Activity[J]. Carbohydrate Polymers, 2019, 213:247-256.

6. Shahrajabian M H, Sun W, Cheng Q . Modern pharmacological actions of Longan fruits and their usages in traditional herbal remedies[J]. Journal of Medicinal Plants Studies, 2019, 7(4):179-185.

7. Ratanachinakorn B, Srithanyarat S, Kotepong P . Quality changes of consumer packed longan[J]. Acta horticulturae, 2010, 65(9):1262-1264.

8. Yang X, Yan F, Huang S, et al. Antioxidant activities of fractions from longan pericarps[J]. Food Science \& Technology, 2014, 34(2):341-345.

9. Insha, Zahoor, Mohammad, et al. Microwave assisted convective drying of bitter gourd: drying kinetics and effect on ascorbic acid, total phenolics and antioxidant activity $[\mathrm{J}]$. Journal of Food Measurement and Characterization, 2019, 13(3):2481-2490.

10. Jing-Kun Yan, Wu L X, Qiao Z R, et al. Effect of different drying methods on the product quality and bioactive polysaccharides of bitter gourd (Momordica charantia L.) slices[J]. Food Chemistry, 2019.271(15): 588-596

11. Junlakan W, Tirawanichakul S, Yamsaengsung R . Effects of vacuum drying on structural changes of bananas, pineapples, and apples[J]. Journal of Food Processing and Preservation, 2017:e13264.

12. Maitê Harguindeguy, Bobba S, Colucci D, et al. Effect of vacuum freeze-drying on the antioxidant properties of eggplants (Solanum melongena L.)[J]. Drying Technology, 2019:1-16.
13. Ahmad, Siti, Anom, et al. Infrared Heating in Food Drying: An Overview[J]. Drying Technology An International Journal, 2015.33(3) : 322-335

14. Fan K , Zhang M , Mujumdar A S . Recent developments in high efficient freeze-drying of fruits and vegetables assisted by microwave: A review[J]. C R C Critical Reviews in Food Technology, 2019, 59(8):13571366.

15. Vongsak B, Sithisarn P, Mangmool S, et al.Maximizing total phenolics, total flavonoids contents and antioxidant activity of Moringa oleifera, leaf extract by the appropriate extraction method[J]. Industrial Crops \& Products, 2013, 44(1):566-571.

16. Salari S , Jafari S M . The Influence of Ohmic Heating on Degradation of Food Bioactive Ingredients[J]. Food Engineering Reviews, 2020, 12(2):191-208.

17. Serdar Öztekin, Martinov M . Medicinal and aromatic crop drying[J]. Stewart Postharvest Review, 2013, 9(2):1-5.

18. Fang $Z$, Bhandari B . Effect of spray drying and storage on the stability of bayberry polyphenols[J]. Food Chemistry, 2011, 129(3):1139-1147.

19. Liu Y, Zeng Y, Guo L, et al. Drying process and quality characteristics of contact ultrasound reinforced heat pump drying on kiwifruit slices[J]. Journal of Food Processing and Preservation, 2019, 43(10).locate the article. References to printed journal articles should typically contain: 